\title{
HTR2 Receptors in a Songbird Premotor Cortical-Like Area Modulate Spectral Characteristics of Zebra Finch Song
}

\author{
William E. Wood, ${ }^{1}$ Thomas K. Roseberry, ${ }^{3}$ and David J. Perkel ${ }^{2,3}$ \\ ${ }^{1}$ Graduate Program in Neurobiology and Behavior, ${ }^{2}$ Department of Biology, and ${ }^{3}$ Department of Otolaryngology, University of Washington, Seattle, \\ Washington 98195
}

\begin{abstract}
Serotonin [5-hydroxytryptamine (5-HT)] is involved in modulating an array of complex behaviors including learning, depression, and circadian rhythms. Additionally, HTR2 receptors on layer V pyramidal neurons are thought to mediate the actions of psychedelic drugs; the native function of these receptors at this site, however, remains unknown. Previously, we found that activation of HTR2 receptors in the zebra finch forebrain song premotor structure the robust nucleus of the arcopallium (RA) led to increased excitation, and that endogenous 5-HT could roughly double spontaneous firing rate. Here, using in vivo single-unit recordings, we found that direct application of 5-HT to these same RA projection neurons, which are analogous to layer $\mathrm{V}$ cortical pyramidal neurons, caused a significant increase in the number of action potentials per song-related burst, and a dramatic decrease in signal-to-noise ratio. Injection of the serotonergic neurotoxin 5,7-dihydroxytryptamine into the third ventricle greatly reduced telencephalic 5-HT and resulted in decreased fundamental frequency of harmonic syllables as well as increased goodness of pitch. Both of these results can be explained by the observed actions of 5-HT on RA projection neurons, and both effects recovered to baseline within 2 weeks following the toxin injection. These results show that 5-HT is involved in modulating spectral properties of song, likely via effects on RA projection neurons, but that adult zebra finches can partially compensate for this deficit within $7 \mathrm{~d}$.
\end{abstract}

\section{Introduction}

The biogenic amine serotonin [5-hydroxytryptamine (5-HT)] is involved in modulating an array of complex behaviors, including learning, anxiety, and mood (Dubovsky and Thomas, 1995; Monti, 2010). 5-HT deficiencies have been closely linked to mental illnesses such as anorexia, obsessive-compulsive disorders, and clinical depression (Ordway et al., 2002; Schatzberg et al., 2002). Understanding the precise loci and mechanisms of action of the serotonergic system - from synapse to behavior- has been difficult due to the complexity of the behaviors and of the system itself. One attractive focus, however, is the action of HTR2 receptors on layer $\mathrm{V}$ pyramidal neurons, where activation by specific agonists (such as LSD, lysergic acid diethylamide) leads to profound perceptual and behavioral changes (Jakab and GoldmanRakic, 1998; Nichols, 2004; Béique et al., 2007).

Songbirds and mammals share an evolutionarily conserved overall brain architecture, with the major exception being that avians lack an obviously layered cortex; instead they have a pal-

Received Sept. 6, 2012; revised Nov. 20, 2012; accepted Dec. 14, 2012.

Author contributions: W.E.W. and D.J.P. designed research; W.E.W. and T.K.R. performed research; W.E.W. T.K.R., and D.J.P. analyzed data; W.E.W. and D.J.P. wrote the paper.

We thank Drs. Gregg Stanwood for help in HPLC and John Neumaier for insights in the methodology of 5,7-DHT lesions. These data appeared in part as posters at the Society for Neuroscience conferences (Wood and Perkel, 2010; Wood et al., 2012).

The authors declare no competing financial interests.

Correspondence should be addressed to David J. Perkel, Departments of Biology and Otolaryngology, Box 356515, University of Washington, Seattle, WA 98195-6515. E-mail: perkel@uw.edu.

T. K. Roseberry's present address: Graduate Program in Neuroscience, University of California, San Francisco, San Francisco, CA 94158.

DOI:10.1523/JNEUROSCI.4291-12.2013

Copyright $\odot 2013$ the authors $\quad 0270-6474 / 13 / 332908-08 \$ 15.00 / 0$ lium with analogous cortical-like areas in distinct regions (Reiner et al., 2004). The song-control system is a set of discrete forebrain nuclei that converge on the robust nucleus of the arcopallium (RA, Fig. 1), which projects directly to the hypoglossal nucleus (nXII) and to brainstem respiratory control nuclei. Projection neurons in RA are hypothesized to be analogous to layer V pyramidal neurons in premotor cortex (Karten, 1969, 1991) and, indeed, can be similarly excited by 5 -HT via HTR2 receptor activation (Wood et al., 2011). In addition to being anatomically accessible, network dynamics within RA are believed to determine spectral characteristics of song, a complex but easily quantifiable learned behavior.

Here, we use in vivo single-unit recordings from RA projection neurons, coupled with playback of a bird's own song (BOS) and focal application of 5-HT- and HTR2-specific agonists into RA, to reveal how HTR2 receptor activity alters song-related firing in these neurons. We then reduced telencephalic 5-HT by injecting 5,7-dihydroxytryptamine (5,7-DHT) into the third ventricle and recorded song production continuously for $>2$ weeks. Acoustic analysis of song syllables revealed specific changes in song production, including decreased fundamental frequency (FF) of harmonic syllables as well as increased "goodness of pitch" (Tchernichovski et al., 2000), a measure of the presence of harmonics. Both of these results can be explained by direct actions of 5-HT on RA projection neurons, which we observed electrophysiologically, and both effects recovered to baseline within 2 weeks following surgery. These results show that 5 -HT is involved in modulating spectral properties of song, likely via effects on RA projection neurons, but that adult zebra finches can partially compensate for this deficit within $7 \mathrm{~d}$. We thus dem- 


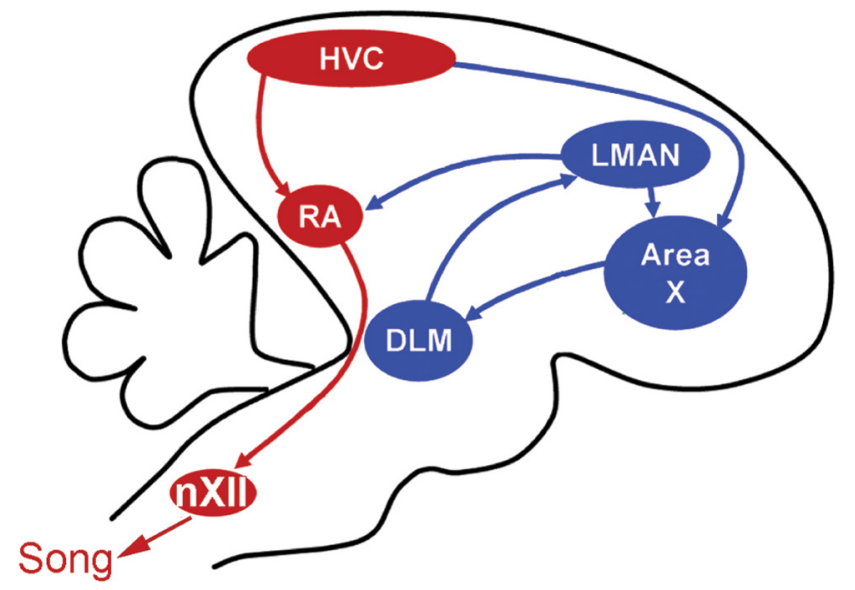

Figure 1. The song-control system is composed of the direct motor pathway (in red) and the anterior forebrain pathway (in blue). HVC may be considered part of both pathways.

onstrate how 5-HT can act at HTR2 receptors on cortical-like premotor projection neurons, finely tuning a complex learned behavior.

\section{Materials and Methods}

\section{Animals}

Adult male zebra finches were obtained from a commercial supplier or reared in our colony. Animals were housed in groups of 4-10 males, on a 13:11 h light/dark cycle, with food and water available ad libitum. All procedures were approved by the University of Washington Institutional Animal Care and Use Committee.

\section{Electrophysiology}

Auditory presentations. Animals were placed in a sound attenuation chamber 1-2 $\mathrm{d}$ before experiments began and BOS was recorded with Sound Analysis Pro (SAP) software (Tchernichovski et al., 2000). Songs were sorted from other cage noises by hand, bandpass filtered (0.1-10 $\mathrm{kHz}$ ) and digitized at $22 \mathrm{kHz}$ using GoldWave Audio Editor. The auditory stimuli for electrophysiology experiments were BOS, BOS played in reverse, conspecific song (the song of another zebra finch), and bursts of noise. The BOS stimulus was the first two motifs from a bout of singing (a motif is a stereotyped sequence of acoustic elements that is repeated during a song bout). Introductory notes preceding the first motif were not included. The duration of BOS averaged $\sim 1.5 \mathrm{~s}$. Conspecific song was chosen to match approximately the duration of BOS and hence varied for each experiment. Noise stimuli were generated from a normal distribution and had the same duration, sampling frequency, and bandpass filter setting as the BOS stimulus. Unmodulated noise had $20 \mathrm{~ms}$ linear onset and offset ramps and the same total power as BOS. Auditory stimuli were presented from a speaker $35 \mathrm{~cm}$ in front of the bird at a peak sound level of 68-72 dB SPL and randomly interleaved with variable intertrial intervals of $10-15 \mathrm{~s}$. Songs were triggered using Spike2 software (Cambridge Electronic Design).

Surgery and recordings. Each animal was given three intramuscular (IM) injections totaling 5-6.6 ml/kg 20\% urethane over $1 \mathrm{~h}$. Local anesthetic ( $1 \%$ lidocaine) was injected under the scalp before the animal was placed in a stereotaxic apparatus with the beak at an angle of $64^{\circ}$ downward from the horizontal. Small craniotomies were made above the midline reference point, the bifurcation of the midsagittal sinus, and above RA. Lidocaine gel was then applied to the incision at $\sim 1 \mathrm{~h}$ intervals, or as necessary. For auditory playback experiments, ear bars were removed after cementing the skull to a metal post and fixing the head via the post.

Glass pipettes (TW100F-3, World Precision Instruments) were pulled using a micropipette puller (Model P97, Sutter Instrument Co.), the tips were blunted to impedances of 10-25 $\mathrm{M} \Omega$, and filled with saline. A ground electrode was placed in the cerebellum posterior to the midline reference point. The recording electrode signal was amplified $10 \times$ and low pass filtered at $3 \mathrm{kHz}$ (Axoclamp 2B amplifier, Molecular Devices), amplified further by $100 \times$ and high pass filtered at $300 \mathrm{~Hz}$ (Model 440, Brownlee Precision). The signal was digitized at $20 \mathrm{kHz}$ and spike times and raw traces were stored for further analysis (Spike2, Cambridge Electronic Design). Principal components analysis of the spike shapes allowed clear separation from noise, although in practice this was mostly unnecessary as we find that with these techniques units in RA generally have a signal-to-noise ratio $>3: 1$. All extracted units obeyed a refractory period of $1 \mathrm{~ms}$, and spike waveforms were automatically overlaid following recording to ensure there were no changes in spike waveform. We are thus confident that recordings were not contaminated by the recruitment of additional neurons. Following successful recordings, $10 \mathrm{kDa}$ dextran amine conjugated to Alexa fluor 488 (Invitrogen) was iontophoretically injected at recording sites for post hoc histological verification of their locations.

All drugs were diluted in a $0.9 \%$ saline solution and pressure ejected from glass pipettes (10-20 $\mu \mathrm{m}$ tip diameter) using a Pressure System IIe (Toohey Co.; $50 \mathrm{~ms}$ pulses at $10 \mathrm{psi}$ ). Injected volumes were $20-100 \mathrm{nl}$. We aimed to place the tip of the injection pipette $200-300 \mu \mathrm{m}$ from the tip of the recording pipette.

Histology. At the end of each experiment, birds were given a lethal dose of sodium pentobarbital via intramuscular injection and perfused transcardially with $0.9 \%$ saline followed by $4 \%$ paraformaldehyde. Brains were cryoprotected in $30 \%$ sucrose dissolved in $0.1 \mathrm{M}$ phosphate buffer (PB) and cut on a freezing microtome into $50 \mu \mathrm{m}$ sections.

Analysis. Spike times were determined with Spike2 and exported to Matlab (MathWorks) using a custom implementation of the SON library. Firing rates were then analyzed in the Matlab environment as follows. For each cell, we calculated spontaneous firing rate, interspike interval (ISI) distribution, and peristimulus time histogram (PSTH) of the response to auditory playback. We determined the average firing rate during song playback, and measured the spontaneous firing rate during a window of the same duration as the song playback preceding the playback. We subtracted the firing rate before song playback from that during playback for each trial, and averaged that value across trials to obtain a mean song response strength (RS; Solis and Doupe, 1997). Songresponse strength measurements were used to calculate the discriminability statistic $d^{\prime}$, which is used to quantify the selectivity of a neuron for a given stimulus over another (Solis and Doupe, 1997), where the difference between the average song RS to two songs was normalized by the square root of the average of the variances of the song response strength $(\sigma)$ measurements for the two songs. Song-evoked bursts were defined as 2 or more spikes firing above $125 \mathrm{~Hz}$ during auditory presentations. We chose $125 \mathrm{~Hz}$ based on a valley in our firing rate histogram, and because it agreed with a previously published criterion (Leonardo and Fee, 2005).

\section{5-HT lesions}

Brain 5-HT levels were drastically reduced by injecting $500 \mathrm{nl}$ of 5,7dihydroxytryptamine creatinine sulfate salt $(5,7-\mathrm{DHT})$ into the third ventricle (coordinates: 0 lateral, -1 rostral, 3.75 deep, $40^{\circ}$ head angle). While 5,7-DHT is a neurotoxin mostly selective for serotonergic terminals (Neumaier et al., 1996), dopaminergic neurotoxicity was blocked by pretreatment with $0.1 \mathrm{ml}$ of desipramine $(2 \mathrm{mg} / \mathrm{ml})$ given by IM injection. Two weeks after injection of either 5,7-DHT or saline, animals were killed by decapitation during isoflurane anesthesia between 9:00 A.M. and 12:00 P.M. Brains were sliced at $300 \mu \mathrm{M}$ using a vibrating microtome (Oxford Instruments) and RA, adjacent arcopallium, HVC, adjacent nidopallium, X, striatum, cerebellum, and brainstem were dissected under light microscopy with micro-dissecting scissors and stored at $-80^{\circ}$. Lesion effectiveness and specificity were verified by HPLC (Vanderbilt University core facility) for a variety of monoamines in these tissue punches. Monoamine levels were expressed as $\mathrm{ng} / \mathrm{mg}$ control protein, calculated via the BCA assay. Brains were sent to be analyzed in a number of batches, and not all regions were analyzed in all batches (marked by N.A. in Table 1 ). While results were generally very consistent, some assays returned obvious outliers and numbers $>4$ SDs outside the average were excluded (light gray in Table 1).

In two instances 5,7-DHT lesioned animals had to be excluded from song analyses: one animal sang extremely rarely, before and after surgery, 
Table 1. HPLC analysis of 5-HT levels following control and 5,7-DHT surgeries

\begin{tabular}{lccc}
\hline Treatment & RA & HVC & Area X \\
\hline 5,7-DHT & 1.46 & 2.42 & 3.72 \\
5,7-DHT & 4.39 & 6.63 & 5.45 \\
5,7-DHT & 0.74 & 2.06 & 2.31 \\
5,7-DHT & 1.95 & N.A. & $\mathbf{1 5 . 0 1}$ \\
5,7-DHT & 7.46 & 5.5 & 4.88 \\
Means & 3.2 & 4.73 & 6.91 \\
Saline & 13.04 & N.A. & 9.64 \\
Saline & 9.41 & 6.83 & 9.17 \\
Saline & 9.53 & 11.22 & 7.27 \\
Saline & 10.35 & 10 & 9.6 \\
0xidized 5,7-DHT & 8.92 & $\mathbf{1 8 4 . 3 9}$ & 10.32 \\
0xidized 5,7-DHT & $\mathbf{1 7 . 7 2}$ & 10.41 & 10.34 \\
Means & $\mathbf{1 0 . 2 5}$ & 9.35 & 9.39 \\
\hline
\end{tabular}

Levels are expressed as nanograms of 5 -HT per milligram of control protein. Not all samples were analyzed in every brain region (N.A., not analyzed). Values in bold font were $>4$ SDs from the mean, and were excluded as outliers.

and was unusable for song analysis. In another instance, equipment malfunction prevented song recording. These two animals thus have HPLC data but no song-analysis data. In two cases saline was injected first and we observed no changes in song parameters. In subsequent attempts to inject 5,7-DHT into those animals, we observed at the time of the injection, that the solution was severely discolored, and we considered it likely that it had oxidized. The conclusion that the 5,7-DHT was inactive was confirmed by the normal 5-HT levels measured in those individuals. We consider these animals to be controls and include song data from them after saline injection.

\section{Song analysis}

Birds were individually housed in sound attenuation chambers (Acoustic Systems) at least $7 \mathrm{~d}$ before and $14 \mathrm{~d}$ after 5-HT lesion surgery. We continually recorded spontaneous (undirected) vocalizations using SAP software. Songs were sorted and analyzed using custom Matlab software and SAP. The acoustic structure of song is arranged in a hierarchy, with 25-250 ms vocal units known as syllables strung together in a stereotyped sequence called a motif. Each song consists of one or several motifs, preceded by introductory notes and separated from each other by $<100$ ms of silence. We used an updated version of a program (Leblois et al., 2010) to sort individual motifs from calls and cage noise. Briefly, after presorting with SAP, the program detected putative motifs based on peaks in the cross-correlation between the spectrogram of the song and that of a clean preselected motif. Such putative motifs were then sorted based on their spectral similarity with the preselected clean motif, using thresholds set by the experimenter. For motifs for which such analysis did not allow unambiguous distinction, an additional PCA analysis on the spectrograms of putative motifs allowed us to sort motifs from other sounds. This analysis allowed us to successfully sort $>90 \%$ of the motifs sung by a bird on a given day (assessed by comparing hand sorting with the automated sorting by the program). Once clean motifs had been sorted, individual syllables were sorted using custom Matlab software somewhat similar to previously reported methods (Wu et al., 2008). Briefly, we ran clean motifs (following the above sorting) through the SAP batch processing module to separate individual syllables and calculate spectral and temporal features. Amplitude threshold was used to determine proper syllable segmentation, and was determined empirically for each individual animal. These data were imported into Matlab and sorted by a semiautomated procedure in which the user selects spectral and temporal feature values for each syllable, as well as the order in which they occur. In summary: songs were presorted in SAP, motifs were cut into individual WAV files with Matlab software, which were then fed back into SAP, where syllables were identified and spectral features were calculated. Spectral data were fed back into Matlab for sorting of syllable types, and final analysis was performed in Matlab, Excel, and Prism Software programs. These methods allowed us to sort and analyze the overwhelming majority of syllables produced daily by each animal over the course of the experiment. When calculating changes over time, each syllable was averaged within a type, and the values per syllable were then averaged to arrive at one value per animal.

\section{Calculation of fundamental frequency}

A $23 \mathrm{~ms}$ spectrally stable portion of the syllable waveform was windowed from onset of harmonic syllables. The power spectrum of the syllable waveform was calculated with frequency bins of $86 \mathrm{~Hz}$. The fundamental frequency of the syllable was calculated from the frequency bin of greatest spectral power using a weighted average from the four neighboring bins and the interharmonic frequency.

\section{Definitions of baseline, lesion, recovery}

Baseline for all birds was established using the average of three stable days in the $1-5 \mathrm{~d}$ before surgery. After surgery, birds often sing little or not at all for a few days, and thus we excluded days following surgery when birds sang $<30 \%$ of the presurgery average number of songs (generally $2-5 \mathrm{~d}$ were excluded). The immediate postlesion period was defined as the first $3 \mathrm{~d}$ following resumption of singing. The recovery period was defined as $7-10 \mathrm{~d}$ following resumption of singing, unless explicitly stated otherwise.

\section{Drug sources}

All drugs were purchased from Sigma-Aldrich: 5,7-Dihydroxytryptamine creatinine sulfate salt (5,7-DHT); Desipramine hydrochloride (desipramine), and Serotonin creatinine sulfate monohydrate (5-HT).

\section{Results}

\section{Serotonin alters song-related electrical activity in premotor nucleus RA}

Serotonin application increased spontaneous firing rate of all RA projection neurons in vivo, as previously reported (Wood et al., 2011). To determine whether this change might be of functional significance to motor output (song), we stimulated RA projection neurons using auditory playback of BOS. We made extracellular single-unit recordings from RA projection neurons in urethane anesthetized animals, in response to BOS playback elicited bursts of firing time-locked to particular syllables and quantitatively similar to those reported during song production in awake animals (Dave, 1998; Hahnloser et al., 2006; Fig. 2). All neurons showed selectivity for BOS compared with all other stimuli tested: conspecific song $\left(\mathrm{CON}\right.$, mean $\left.d^{\prime}=2.97\right)$; white noise $\left(d^{\prime}=3.34\right)$; or BOS played in reverse (REV, $d^{\prime}=1.91$, Fig. $3 A$ ).

Pressure application of $\sim 5-50 \mathrm{nl}$ of $1 \mathrm{~mm}$ 5-HT near the recording site caused a significant increase in the number of spikes per BOS-evoked burst (13.9\% increase, Friedman test, Dunn's Multiple Comparison post hoc test, $p=0.0239, \Delta=0.39$ spikes per burst, $n=5$ neurons in 4 animals, Friedman statistic $=7.6$, Fig. $3 B)$, an increase in the length of BOS-evoked bursts $(19.4 \%$ increase, paired $t$ test: $p=0.0407, \Delta=1.483 \mathrm{~ms}, n=5$ neurons in 4 animals, $t=2.982$, $\mathrm{df}=4$, Fig. $3 C$ ). As we previously reported, spontaneous activity (non-BOS-evoked) increased dramatically (217\% increase, paired $t$ test: $p<0.0001, \Delta=26.47 \mathrm{~Hz}, n=9, t=$ 7.240 , df $=8$, Wood et al., 2011). Spontaneous activity thus shows the most increase by far.

Signal-to-noise ratio can be calculated as the ratio of songrelated spikes (bursts) to the number of spikes not related to song activity (spontaneous activity). Spontaneous activity, which nearly doubled, experienced a greater increase in firing rate than song-related bursts, which increased by only $\sim 1$ spike per burst (Figs. 2, 3B) resulting in a robust decrease in signal-to-noise ratio (Fig. $3 D, p=0.0041, \Delta=-1.64, n=5$ neurons in 4 birds, $t=$ $5.925, \mathrm{df}=4)$. There was no similar change in the RS to either REV or CON (paired $t$ test: $p=0.72$ and 0.41 , respectively).

Since activity in RA is widely held to shape spectral properties of song these results make two predictions for how 5-HT affects adult song spectral characteristics. First, as 5-HT decreases the 


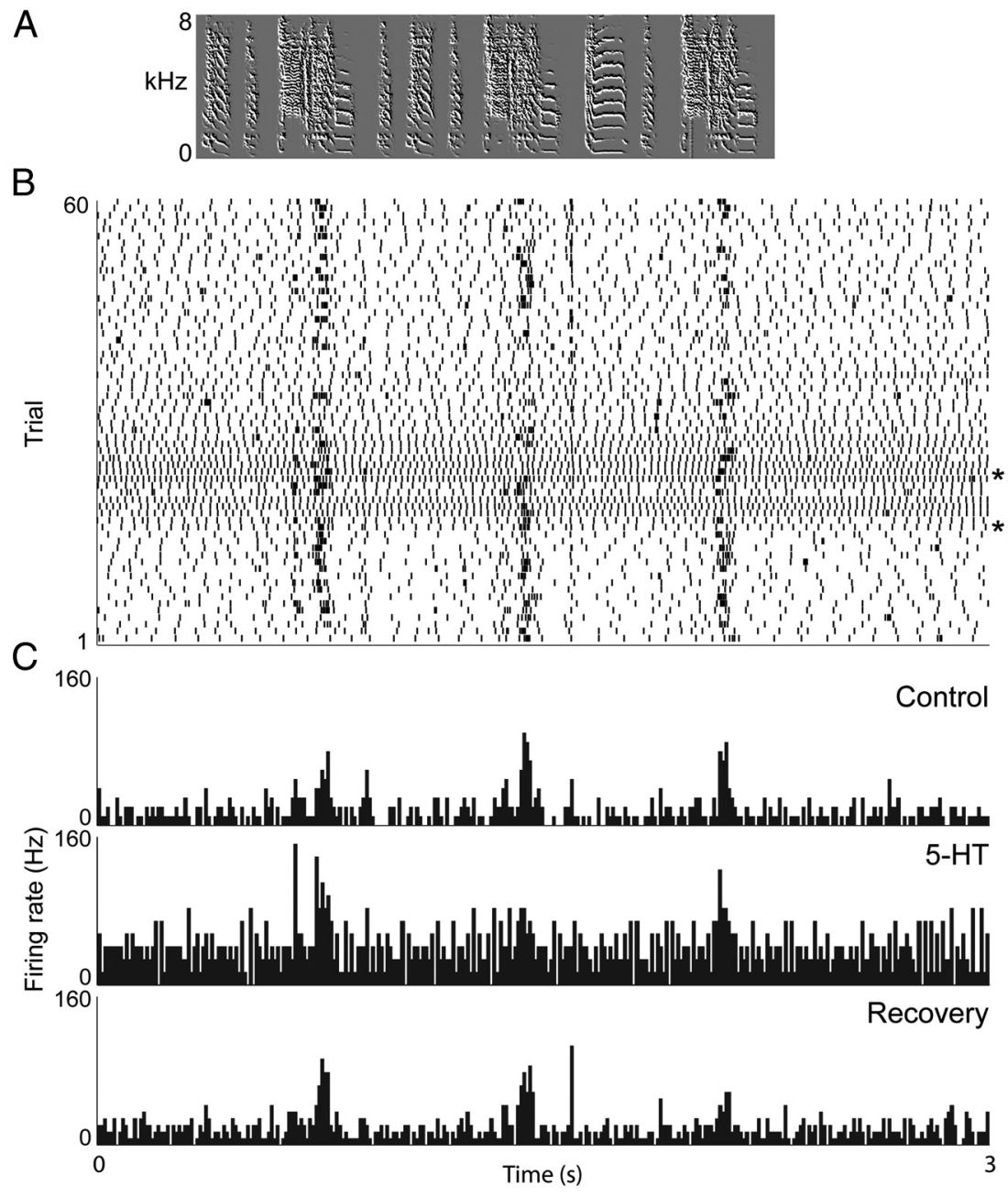

Figure 2. Example of in vivo spiking patterns in RA projection neurons with 5-HT application and BOS presentation. Neurons fired more in general, and also fired more song-related spikes during bursts. $A$, Waveform and spectrogram of BOS. All panels are aligned to $\boldsymbol{A}$. $\boldsymbol{B}$, Raster plot of spikes from an RA projection neuron selective for B0S. 5-HT was applied at the 2 asterisks. $\boldsymbol{C}$, Histogram of spike activity from control, 5 -HT and recovery periods.
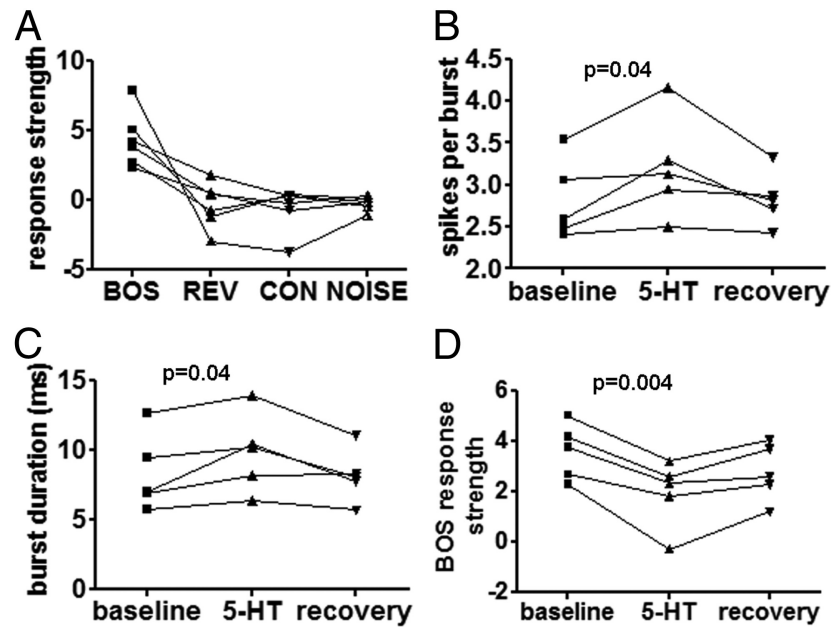

Figure 3. Quantification of song-evoked spiking patterns in RA projection neurons with 5-HT application. Neurons fired more in general, and also fired more song-related spikes during bursts, $n=5$ neurons in 4 animals. $A$, RA neurons were selective for BOS over reverse BOS, conspecific song, or white noise. $\boldsymbol{B}$, Application of 5 -HT significantly increased the number of spikes per burst evoked by BOS. C, 5-HT also significantly increased the duration of bursts evoked by BOS. D, Response strength decreased with application of $5-\mathrm{HT}$, primarily due to the increase in spontaneous firing rate that 5-HT causes. signal-to-noise ratio of song-related activity in RA, 5-HT may make song noisier and less precise. Second, as 5-HT increases the number of spikes per burst, and since these bursts lead to activity in the syrinx, 5-HT can be predicted to cause increased contractions in the syrinx, resulting in, on average, higher frequency songs (Sober et al., 2008). Removing 5-HT from RA would thus be expected to (1) lower the frequency of songs and (2) decrease syllabic entropy and increase the goodness of pitch. To test these hypotheses we lesioned the 5-HT system in adult male zebra finches.

\section{Monoamine levels following serotonin lesions}

Lesioned animals had significantly lower 5 -HT levels in all brain regions tested (for RA: $9.537 \pm 0.75 \mathrm{ng}, n=5$ vs $3.2 \pm 1.229$ ng, $n=7$ following 5,7-DHT injections; unpaired $t$ test: $p=0.0009, t=4.657, \mathrm{df}=$ 10; Table 1), while norepinephrine and dopamine levels were unaffected $(p=$ 0.25 and 0.65 for RA, respectively; data not shown). All brain regions tested had similar reductions in 5 -HT (Table 1 ), but here we focus on levels in RA.

\section{Spectral song analysis}

All animals sang relatively normal songs following lesion/sham surgery (Fig. 4A), allowing us to compare syllables before and after treatment.

We measured the frequency of song syllables using SAP's "mean frequency" measure, which quantifies the central tendency of syllable frequency. As predicted by in vivo electrophysiological data, syllable frequency was consistently and significantly reduced following 5-HT lesions (Fig. 4B). This reduction was observed immediately after surgery (days 1-3, unpaired $t$ test: $p=0.0126$, $\Delta=-189.7 \pm 62.04 \mathrm{~Hz}, t=3.328, \mathrm{df}=7)$ and remained significant 2 weeks later (Fig. $4 B$, days 13-15, unpaired $t$ test: $p=$ $0.0026, \Delta=-178.7 \pm 29.32 \mathrm{~Hz}, t=4.301, \mathrm{df}=8)$. Furthermore, the change in mean frequency 2 weeks postsurgery (when 5-HT levels were measured) was correlated with 5-HT levels in RA (Fig. $\left.4 C, p=0.0082, R^{2}=0.6032, F=12.16\right)$. One data point appeared to be an outlier, although it is consistent with the trend established without it ( $p=0.0646, R^{2}=0.4068, F=4.8$ ).

Similarly, FF of harmonic syllables decreased after lesion surgery (Fig. $5 A, p=0.035, \Delta=-72.5 \pm-36.6 \mathrm{~Hz}$ drop in lesion group vs $\Delta=0.4 \pm 6.2 \mathrm{~Hz}$ in control animals). Following the initial decline, FF slowly recovered to baseline with a trajectory and timescale suggestive of compensatory learning (Fig. $5 A$, recovery of $11.03 \pm 2.102 \mathrm{~Hz} / \mathrm{d}$ ). These findings are in agreement with the generally accepted role of RA in determining spectral properties of song, and suggest that bursts in RA, and serotonin's effects on them, play a role in determining the frequency of syllables.

Electrophysiological data also predicted that animals with depleted 5-HT would produce more exact syllables, due to in- 
creased signal-to-noise ratio. Indeed, we observed a significant increase in goodness of pitch (the peak of the derivativecepstrum calculated for harmonic pitch; SAP manual). This effect was quite strong in the first days following lesion (Fig. $5 B$, $\Delta=33.5 \pm 3.5, p<0.0001$ ) but, similar to $\mathrm{FF}$, goodness of pitch recovered to baseline by days $13-15(p=0.65)$. No other measures of song structure changed, including motif stereotypy (syllable order), syllable duration, and Wiener entropy.

\section{Song production rate in morning and evening}

Serotonin is implicated in controlling circadian behaviors, and we investigated the effect of 5-HT lesions on daily changes in song patterns. As birds tend to sing most in the morning, we asked whether 5-HT lesions alter the fraction of songs sung in the morning versus evening. There was no change in either the total number of songs sung by controls versus lesioned animals or in the ratio of songs sung in the morning versus evening (Fig. 6, paired $t$ test, $p=0.384$, df $=4$ ). While the amount of singing was quite variable between animals and may obscure slight effects, these findings do indicate that 5 -HT is not critically involved in determining when, or how much, a bird sings.

\section{Discussion}

HTR2 receptors are present on RA projection neurons, and their activation with either 5-HT or the specific agonist DOI causes an increase in excitability (Wood et al., 2011). Here, we found that activation of these receptors during playback of BOS leads to (1) increased song-related burst activity and (2) increased spontaneous firing, leading to (3) a decreased signal-to-noise ratio. To understand how these actions affect the motor output of this circuit (song), we then lesioned the serotonergic system with 5,7DHT and analyzed song. Fundamental frequency decreased and goodness of pitch increased, in keeping with findings 1 and 2 above.

The role of 5-HT in BOS selective auditory responses in RA Application of 5-HT had a relatively weak effect on BOS-evoked bursts of activity in RA projection neurons, on average increasing spikes per burst by 0.39 . While significant, it is a much smaller effect than the approximate doubling in spontaneous firing rate we consistently observe in all RA projection neurons. BOSrelated bursts in RA in adult zebra finches appear to be robust to perturbations - a finding not at all surprising in an animal that sings a single song for the entirety of its adult life. The most likely biophysical mechanism underlying this increase in action potentials is an interaction between a direct increase in excitability of RA projection neurons due to HTR2-mediated depolarization with incoming synaptic inputs from HVC, although increased baseline subthreshold activity and the nonlinearity due to the action potential threshold may also play a role.

There is tonic release of 5-HT in RA. We know this because HPLC reveals 5-HT in RA (Barclay and Harding, 1988) and because direct application of the selective serotonin reuptake inhib-
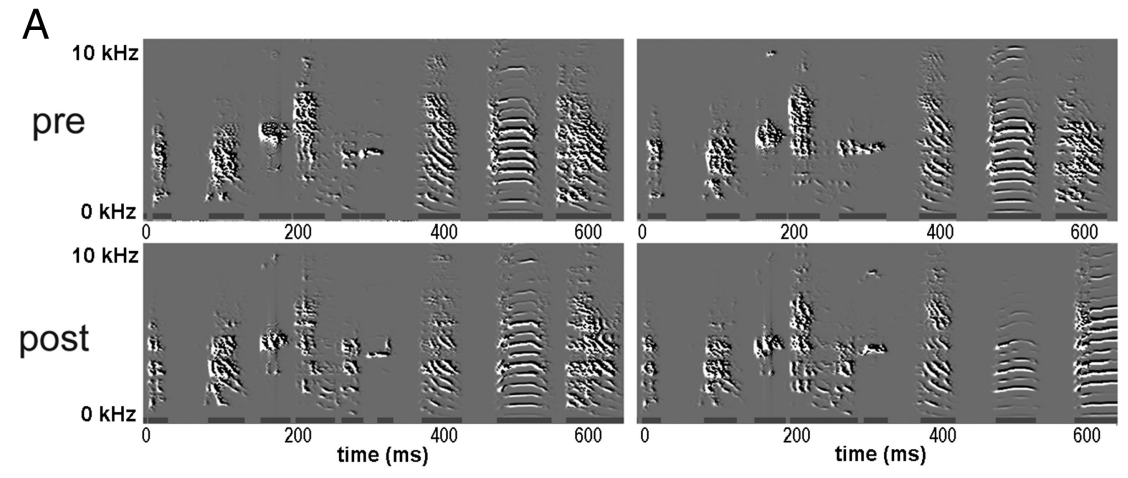

C

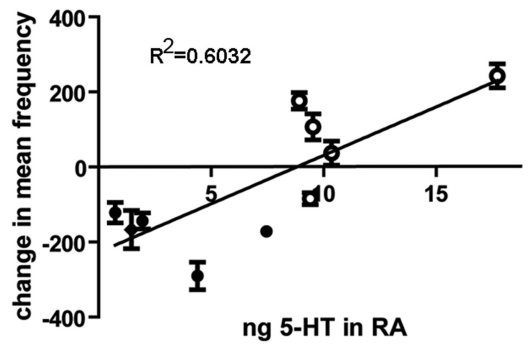

ng 5-HT in RA

Figure 4. $\quad \boldsymbol{A}$, Example spectrograms before (top) and after (bottom) 5-HT lesion surgery. Song was left largely intact. $\boldsymbol{B}$, Mean frequency of syllables was significantly reduced 2 weeks after lesion (days $13-15, p=0.0026, \Delta-178.7 \pm 29.32 \mathrm{~Hz}, n=5$ animals per group). $\boldsymbol{C}$, 列 $p=0.0082, R^{2}=0.6032$ ). Closed circles represent lesioned animals, open circles represent controls. Each data point in $\boldsymbol{B}$ and $\boldsymbol{C}$ corresponds to the mean of syllables for one animal, with each syllable type sorted and analyzed separately.
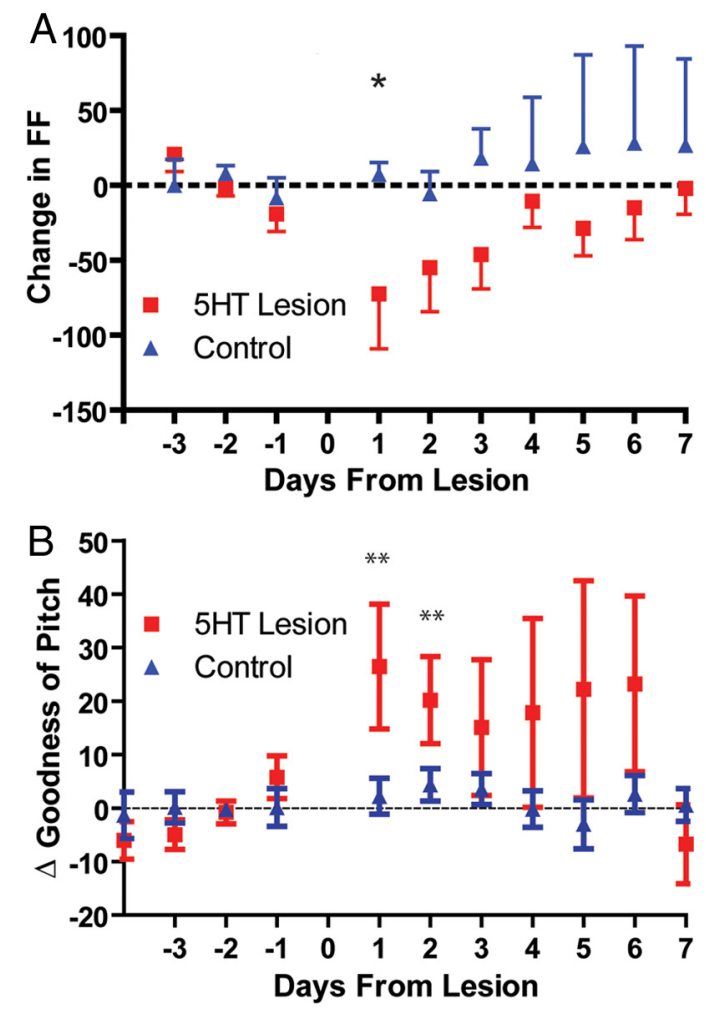

Figure 5. Fundamental frequency and goodness of pitch of syllables were transiently altered in 5-HT lesioned animals $(n=5)$, but not controls $(n=5)$. $A$, Lesioned animals had reduced FF immediately following surgery, while control animals did not $(p=0.035, \Delta=-72.5 \pm$ $-36.6 \mathrm{~Hz}$ immediately following surgery). This effect recovered to baseline within a week, with a trajectory and timescale suggestive of learning. $\boldsymbol{B}$, Goodness of pitch was significantly increased in lesioned animals in the first days following surgery but not in control animals. 

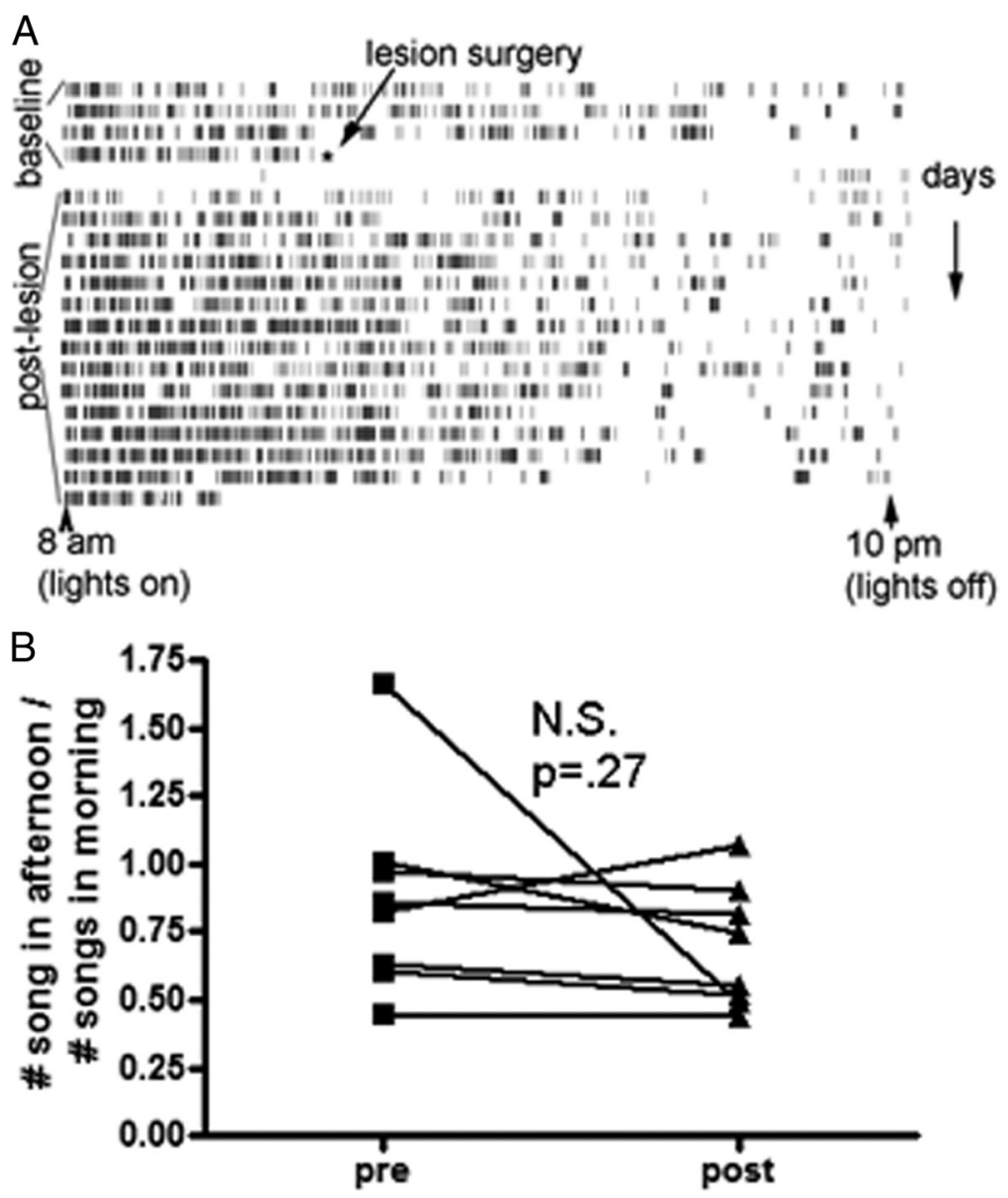

Figure 6. Birds tended to sing more in the morning than in the afternoon, and 5-HT lesions did not interfere with this pattern. A, A representative animal's song production data. Each tick mark represents 1 motif. This bird did not sing for $\sim 1 \mathrm{~d}$ following surgery but song production was back to normal after $\sim 3 \mathrm{~d}$. The missing songs on the morning of the third day following surgery reflect software malfunction and were excluded from analysis. $\boldsymbol{B}$, There were no significant differences in when birds sang following the 5-HT lesion ( $n=5)$; here we plot the ratio of afternoon to morning songs (2:00-4:00 P.M. vs 8:00-10:00 A.M.) for the $3 \mathrm{~d}$ before surgery and after 2 weeks following surgery. No effects were apparent at any time following acute recovery from surgery.

itor fluvoxamine results in increased firing rate in these neurons (Wood et al., 2011). One possible experiment would be to block the actions of 5-HT on these neurons via specific antagonists during BOS playback. A number of cautionary findings, however, caused us to avoid this manipulation. Primary is that application of 5-HT has such a subtle effect on BOS-evoked bursts. Experimentally, application of 5-HT is in a sense its own positive control, as we can be assured the pipette is not blocked and is applying 5-HT since FR increases drastically even as burst activity increases only modestly. Application of antagonists would have no similar internal control, and the expected minimal decrease in burst activity would thus be exceedingly difficult to uncover. It is worth noting that 5-HT can affect auditory processing at other levels (Hurley and Hall, 2011).

\section{The role of 5-HT in determining adult song features}

Injection of 5,7-DHT into the third ventricle substantially reduced 5-HT levels across the telencephalon. Consistent with studies in other organisms, animals functioned almost completely normally following lesions (Smale et al., 1990; Neumaier et al., 1996), songs were generally indistinguishable from baseline, and animals sang a similar amount during similar times of day compared with baseline periods (Fig. 6). Our electrophys- iological data indicate that 5-HT increases spikes per song-related burst in RA projection neurons, which are thought to shape spectral properties of song ( $\mathrm{Yu}$ and Margoliash, 1996). RA has a direct projection to the hypoglossal nucleus, which projects directly to the syrinx. Bursts in RA lead to muscle contractions in the syrinx. Avian song production involves muscle contraction driven apposition of the syringeal labia coincident with expiration (Goller and Suthers, 1996a). Further contraction, increasing tension, produces sounds with higher fundamental frequencies. According to Goller and Suthers (1996b) (p. 287), "EMG activity in musculus syringealis ventralis $(\mathrm{vS})$, the largest syringeal muscle, increases exponentially with the fundamental frequency of the ipsilaterally generated sound and closely parallels frequency modulation." Additionally, a dynamical model based on these observations reproduces frequency sweeps when run with either simulated functions representing tensions in vocal muscles (Gardner et al., 2001; Laje et al., 2001) or with transformed EMG activity recorded from singing birds (Mindlin et al., 2003). While we would not expect to find an exact linear match between large changes in activity in RA and FF, the strong dependence upon excitation in $\mathrm{vS}$ and FF does indicate that small changes in RA activity, such as those seen in this study, would be expected to change the FF of songs-as observed here. Furthermore, the variation in number of spikes in RA projection neurons has been shown to significantly correlate with syllable FF, and while the authors did not seem to quantify the number of positive correlations versus negative correlations, it appears to be $\sim 2: 1$ (Sober et al., 2008).

Reducing 5-HT in RA should lead to fewer action potentials per burst and thus to less muscle tone in the syrinx (Vicario and Nottebohm, 1988; Abarbanel et al., 2004; Fiete et al., 2007). This supports the idea that spectral properties of song are primarily determined by RA (Fee et al., 2004; Fiete et al., 2007; Gibb et al., 2009). Removing 5-HT from RA, then, should lead to a decrease in the frequency (approximate pitch) of syllables. In agreement with this hypothesis, FF of harmonic syllables was significantly reduced following lesions (Figs. $4 B, 5 A$ ), and the amount of 5-HT in RA was linearly correlated with change in FF following lesion (Fig. 4C). While we consider RA to be the most likely locus for 5-HT-mediated changes to spectral features of song, there are of course other possibilities. 5-HT receptors are expressed in other areas of the song control system, including HVC and area X (Dutar et al., 1998; Lovell and Mello, 2012), and 5-HT is known to modulate auditory responses in other species (Hurley and Hall, 2011).

Goodness of pitch, which is an estimate of harmonic pitch periodicity, was increased following 5-HT lesion. Reduced 5-HT in RA leads to reduced spontaneous activity, which leads to increased signal-to-noise ratios during song-related bursting. One 
interpretation of this result is that harmonic stacks were less modulated ("cleaner") following lesion (increased goodness of pitch), primarily due to an increased signal-to-noise ratio in RA. We did not, however, observe a concomitant decrease in spectral entropy which might also have been expected.

5 -HT is necessary for proper body-temperature regulation in a mouse model involving acute serotonergic neuron inhibition (Ray et al., 2011). If this is true in birds as well, it is possible that some of the effects we observed may be partially explained via a decrease in brain temperature and associated downstream effects. Previous studies cooling the avian brain found the most drastic effects occurred in a lengthening of song tempo, however, and the lack of that finding here argues against this hypothesis (Long and Fee, 2008).

It is perhaps surprising that changes in song following 5-HT lesion recovered to normal, particularly given the known importance of serotonin in learning (Harvey, 2003). It would seem 5 -HT is not necessary for song maintenance in adult song zebra finches. Interestingly, the recovery to baseline seemed to depend more on amount of singing than on the time since surgery (data were by necessity, aligned to resumption of singing, which led to a robust time dependence of recovery of FF, Fig. 5A), suggesting an activity-dependent mechanism. This could be due to adult error correction, although it would be slower than that seen in other scenarios (Andalman and Fee, 2009; Sober and Brainard, 2009; Charlesworth et al., 2012). An alternative possibility is the potential for activity-dependent expression of serotonin receptors in the song system, supported by the previous finding that HTR2 binding increases following 5-HT lesions in a rodent model (Compan et al., 1998). We cannot differentiate between these hypotheses at this time. A final point to note is that mean frequency did not recover during the experiments. Why one measure of syllable frequency did recover while the other did not is initially vexing, although two possibilities seem probable. One is that birds, similarly to humans, may find FF to be a more salient feature than mean frequency, and thus the birds may correct alterations in FF more rapidly than they do alterations to mean frequency. Second, we took great pains to ensure that our FF measurement occurred on stable portions of harmonic stacks, which may be more tractable to adult error correction than noisier complex syllables.

This study reveals that 5-HT acts in forebrain premotor circuits to alter complex learned behavior. The conserved nature of the serotonergic system (Hen, 1993) indicates the findings here are likely to generalize across vertebrates. This greater mechanistic understanding of particular actions of 5-HT on song production in songbirds will lead to improved knowledge of how 5-HT modulates neural activity underlying perception and behavior in mammals.

\section{References}

Abarbanel HDI, Gibb L, Mindlin GB, Talathi S (2004) Mapping neural architectures onto acoustic features of birdsong. J Neurophysiol 92:96-110. CrossRef Medline

Andalman AS, Fee MS (2009) A basal ganglia-forebrain circuit in the songbird biases motor output to avoid vocal errors. Proc Natl Acad Sci U S A 106:12518-12523. CrossRef Medline

Barclay SR, Harding CF (1988) Androstenedione modulation of monoamine levels and turnover in hypothalamic and vocal control nuclei in the male zebra finch: steroid effects on brain monoamines. Brain Res 459: 333-343. CrossRef Medline

Béique JC, Imad M, Mladenovic L, Gingrich JA, Andrade R (2007) Mechanism of the 5-hydroxytryptamine $2 \mathrm{~A}$ receptor-mediated facilitation of synaptic activity in prefrontal cortex. Proc Natl Acad Sci U S A 104:98709875. CrossRef Medline
Charlesworth JD, Warren TL, Brainard MS (2012) Covert skill learning in a cortical-basal ganglia circuit. Nature 486:251-255. Medline

Compan V, Segu L, Buhot MC, Daszuta A (1998) Selective increases in serotonin $5-\mathrm{HT} 1 \mathrm{~B} / 1 \mathrm{D}$ and $5-\mathrm{HT} 2 \mathrm{~A} / 2 \mathrm{C}$ binding sites in adult rat basal ganglia following lesions of serotonergic neurons. Brain Res 793:103-111. CrossRef Medline

Dave AS (1998) Behavioral state modulation of auditory activity in a vocal motor system. Science 282:2250-2254. CrossRef Medline

Dubovsky SL, Thomas M (1995) Serotonergic mechanisms and current and future psychiatric practice. J Clin Psychiatry 56 [Suppl 2]:38-48.

Dutar P, Vu HM, Perkel DJ (1998) Multiple cell types distinguished by physiological, pharmacological, and anatomic properties in nucleus $\mathrm{HVC}$ of the adult zebra finch. J Neurophysiol 80:1828-1838. Medline

Fee MS, Kozhevnikov AA, Hahnloser RHR (2004) Neural mechanisms of vocal sequence generation in the songbird. Ann N Y Acad Sci 1016: 153-170. CrossRef

Fiete IR, Fee MS, Seung HS (2007) Model of birdsong learning based on gradient estimation by dynamic perturbation of neural conductances. J Neurophysiol 98:2038-2057. CrossRef Medline

Gardner T, Cecchi G, Magnasco M, Laje R, Mindlin GB (2001) Simple motor gestures for birdsongs. Phys Rev Lett 87:208101. CrossRef Medline

Gibb L, Gentner TQ, Abarbanel HDI (2009) Inhibition and recurrent excitation in a computational model of sparse bursting in song nucleus HVC. J Neurophysiol 102:1748-1762. CrossRef Medline

Goller F, Suthers RA (1996a) Role of syringeal muscles in gating airflow and sound production in singing brown thrashers. J Neurophysiol 75:867876. Medline

Goller F, Suthers RA (1996b) Role of syringeal muscles in controlling the phonology of bird song. J Neurophysiol 76:287-300. Medline

Hahnloser RHR, Kozhevnikov AA, Fee MS (2006) Sleep-related neural activity in a premotor and a basal-ganglia pathway of the songbird. J Neurophysiol 96:794-812. CrossRef Medline

Harvey JA (2003) Role of the serotonin 5-HT(2A) receptor in learning. Learn Mem 10:355-362. CrossRef Medline

Hen R (1993) Structural and functional conservation of serotonin receptors throughout evolution. EXS 63:266-278. Medline

Hurley LM, Hall IC (2011) Context-dependent modulation of auditory processing by serotonin. Hear Res 279:74-84. Medline

Jakab RL, Goldman-Rakic PS (1998) 5-Hydroxytryptamine2A serotonin receptors in the primate cerebral cortex: Possible site of action of hallucinogenic and antipsychotic drugs in pyramidal cell apical dendrites. Proc Natl Acad Sci U S A 95:735-740. CrossRef Medline

Karten H (1969) Comparative and evolutionary aspects of the vertebrate central nervous system. Ann NY Acad Sci 167:164-179. CrossRef

Karten HJ (1991) Homology and evolutionary origins of the "neocortex." Brain Behav Evol 38:264-272. CrossRef Medline

Laje R, Gardner T, Mindlin GB (2001) Continuous model for vocal fold oscillations to study the effect of feedback. Phys Rev E Stat Nonlin Soft Matter Phys 64:056201. CrossRef

Leblois A, Wendel BJ, Perkel DJ (2010) Striatal dopamine modulates basal ganglia output and regulates social context-dependent behavioral variability through D1 receptors. J Neurosci 30:5730-5743. CrossRef Medline

Leonardo A, Fee MS (2005) Ensemble coding of vocal control in birdsong. J Neurosci 25:652-661. CrossRef Medline

Long MA, Fee MS (2008) Using temperature to analyse temporal dynamics in the songbird motor pathway. Nature 456:189-194. CrossRef Medline

Lovell PV, Mello CV (2012) ZEBrA database [WWW Document]. Oregon Health and Sciences University. http://www.zebrafinchatlas.org.

Mindlin GB, Gardner TJ, Goller F, Suthers R (2003) Experimental support for a model of birdsong production. Phys Rev E Stat Nonlin Soft Matter Phys 68:041908. CrossRef Medline

Monti JM (2010) Serotonin 5-HT(2A) receptor antagonists in the treatment of insomnia: present status and future prospects. Drugs Today (Barc) 46:183-193. CrossRef

Neumaier JF, Szot P, Peskind ER, Dorsa DM, Hamblin MW (1996) Serotonergic lesioning differentially affects presynaptic and postsynaptic 5-HT1B receptor mRNA levels in rat brain. Brain Res 722:50-58. CrossRef Medline

Nichols DE (2004) Hallucinogens. Pharmacol Ther 101:131-181. CrossRef Medline

Ordway G, Klimek V, Mann J (2002) Chapter 73: Neurocircuitry of mood 
disorders. In: Neuropsychopharmacology: the fifth generation of progress (Davis K, Charney D, Coyle J, Nemeroff C, eds). Philadelphia: Lippincott Williams \& Wilkins.

Ray RS, Corcoran AE, Brust RD, Kim JC, Richerson GB, Nattie E, Dymecki SM (2011) Impaired respiratory and body temperature control upon acute serotonergic neuron inhibition. Science 333:637-642. CrossRef Medline

Reiner A, Perkel DJ, Bruce LL, Butler AB, Csillag A, Kuenzel W, Medina L, Paxinos G, Shimizu T, Striedter G, Wild M, Ball GF, Durand S, Güntürkün O, Lee DW, Mello CV, Powers A, White SA, Hough G, Kubikova L, et al. (2004) Revised nomenclature for avian telencephalon and some related brainstem nuclei. J Comp Neurol 473:377-414. CrossRef Medline

Schatzberg A, Garlow S, Nemeroff C (2002) Chapter 72: Molecular and cellular mechanisms in depression. In: Neuropsychopharmacology: the fifth generation of progress (Davis K, Charney D, Coyle J, Nemeroff C, eds). Philadelphia: Lippincott Williams \& Wilkins.

Smale L, Michels KM, Moore RY, Morin LP (1990) Destruction of the hamster serotonergic system by 5,7-DHT: effects on circadian rhythm phase, entrainment and response to triazolam. Brain Res 515:9-19. CrossRef Medline

Sober SJ, Brainard MS (2009) Adult birdsong is actively maintained by error correction. Nat Neurosci 12:927-931. CrossRef Medline

Sober SJ, Wohlgemuth MJ, Brainard MS (2008) Central contributions to acoustic variation in birdsong. J Neurosci 28:10370-10379. CrossRef Medline
Solis MM, Doupe AJ (1997) Anterior forebrain neurons develop selectivity by an intermediate stage of birdsong learning. J Neurosci [Erratum (1999) 1:preceding I] 17:6447-6462. Medline

Tchernichovski O, Nottebohm F, Ho CE, Pesaran B, Mitra PP (2000) A procedure for an automated measurement of song similarity. Anim Behav 59:1167-1176. CrossRef Medline

Vicario DS, Nottebohm F (1988) Organization of the zebra finch song control system: I. Representation of syringeal muscles in the hypoglossal nucleus. J Comp Neurol 271:346-354. CrossRef Medline

Wood WE, Lovell PV, Mello CV, Perkel DJ (2011) Serotonin, via HTR2 receptors, excites neurons in a cortical-like premotor nucleus necessary for song learning and production. J Neurosci 31:13808-13815. CrossRef Medline

Wood WE, Perkel DJ (2010) Serotonergic modulation of auditory activity in zebra finch song nucleus RA. Soc Neurosci Abstr 36:207.3.

Wood WE, Roseberry TK, Perkel DJ (2012) Decreased serotonin in a cortical-like premotor song area (RA) reduces average fundamental frequency of song syllables and also interferes with circadian rhythms of fundamental frequency. Soc Neurosci Abstr 38:205:20.

Wu W, Thompson JA, Bertram R, Johnson F (2008) A statistical method for quantifying songbird phonology and syntax. J Neurosci Methods 174: 147-154. CrossRef Medline

Yu AC, Margoliash D (1996) Temporal hierarchical control of singing in birds. Science 273:1871-1875. CrossRef Medline 